\title{
Cornelia Faventina: estatus jurídico liberto y promoción social femenina en Tarraco
}

\section{Cornelia Faventina: Freedperson juridical status and female social mobility in Tarraco}

\section{Clara María Ramos-Taboada}

Universidade de Santiago de Compostela. Facultade de Xeografía e Historia. Departamento de Historia Praza da Universidade, 1, E-15782 Santiago de Compostela claramaria.ramos@usc.es

El objetivo de nuestro artículo es analizar la figura y el círculo familiar de Cornelia Faventina, mujer atestiguada en la epigrafía de la Colonia Urbs Triumphalis Tarraco. Proponemos su estatus liberto utilizando una serie de marcadores epigráficos y onomásticos combinados con el análisis de su comportamiento epigráfico, tanto como dedicante individual como a través de la comparación con el de otras dos mujeres hispanas de contextos dispares. Su promoción social, constatable a través del matrimonio con un duovir, la convierte en un caso excepcional dentro del patrón matrimonial propio de los libertos en Roma y en la Hispania romana.

\section{PALABRAS CLAVE}

TARRACO, EPIGRAFÍA, LIBERTAE, LIBERTOS, MUJER ROMANA, FAMILIA ROMANA

This publications aims to study the evidence concerning Cornelia Faventina, a woman attested in the epigraphy of the Colonia Urbs Triumphalis Tarraco. We make use of new onomastic and epigraphic markers which allow us to propose that she was a freedwoman. This conclusion will be reinforced by comparing her epigraphic representation with two relevant cases of Hispanic women from different backgrounds. Her social promotion, clearly attested by her marriage to a duovir, presents her as an exceptional case in the freedpersons' pattern of marriage in Rome and in Hispania.

\section{KEYWORDS}

TARRACO, EPIGRAPHY, LIBERTAE, FREEDPERSONS, ROMAN WOMEN, ROMAN FAMILY 


\section{Introducción}

Urbanización, manumisión y epigrafía son tres realidades interconectadas en el mundo romano. Por ese motivo, ante la insuficiencia de fuentes literarias, los estudios sobre la posible existencia de una identidad liberta se han concentrado en Roma y zonas itálicas urbanizadas.

Para Hispania, se han realizado recopilaciones de las inscripciones latinas de esclavos y libertos de la península ibérica, pero los estudios prosopográficos sobre individuos concretos son raramente viables; apenas si cabe mencionar el caso de Licinio Segundo, liberto de Licinio Sura (Rodà de Llanza, 1970).

Nuestra intención es abordar una de esas excepciones en las que varios epígrafes presentan a un mismo individuo, Cornelia Faventina, cuyo interés es todavía mayor por ser mujer, ya que son casos incluso más infrecuentes. Su estudio ha sido, hasta ahora, insuficiente y precario. Aparte del tratamiento de los epígrafes en diferentes corpora cuya procedencia fue corregida repetidamente, los historiadores han dedicado escasa atención a este personaje, llegando a conclusiones confusas e incluso erróneas.

Contamos con breves referencias (Schulze-Oben, 1989: 246) donde es citada como doble dedicante hermana, pero sin precisar estatus y estableciendo su origen en Iesso; también breves comentarios sobre el soporte de las piezas (Álvarez et al., 2009: 15, 61, 75, 82, 93, 133, 159; Gutiérrez, 2009: 21 1, 214). Sin embargo, el mejor análisis hasta el momento lo encontramos en la reciente obra de Milagros Navarro Caballero (2017: 126, 213, 216 , 601,602 , 608), aunque con un comentario muy sucinto (Nr. 338).

Mayor atención le ha dedicado Liborio Hernández Guerra, quien toma a Faventina como liberta sin exponer ningún marcador para su identificación como tal (2006). La encontramos en los registros n. ${ }^{\circ} 99$ y n. ${ }^{\circ} 100$ de su catálogo, sin mencionar su nomen ni si es una mujer o dos homónimas, situándola en Iesso y considerando los epígrafes en los que aparece (sin identificar su papel en ellos) como funerarios. Citados en el cuerpo del texto, (Hernández Guerra, 2006: 122, 135), ambos registros se analizan como casos de matrimonio(s) con seviri augustales. Esta exposición es absolutamente errónea ya que Faventina no indica en su onomástica que sea liberta; los epígrafes en los que está presente son cuatro y no dos; en todos se menciona su nomen; no está casada con seviri, pues estos son sus hermanos y, pese a que las inscripciones fueron trasladadas de lugar en época moderna, el origen común de todas ellas se halla en Tarraco.

En su monografía sobre libertos en Hispania, la mención a Faventina es nula, catalogando tan solo a un Faventinus, pese a que establece un plural, "los Faventinus» de Iluro (Hernández Guerra, 2013: 45, 200).

Finalmente, en el que constituye el catálogo más actualizado de inscripciones de libertos en la península ibérica (Hernández Guerra, 2016), encontramos a Faventina (registros 941, 942, 943, 1914) como liberta, pero sin ningún tipo de aclaración. Vuelve a caer en la contradicción sobre la aparición del registro 1914 en Iesso y el 942 (duplicado del anterior, pero tomando como referencia a la dedicante) en Tarraco. No hay rastro de la cuarta dedicación existente. 
Por tanto, en nuestro estudio planteamos primeramente un estatus jurídico liberto para Cornelia Faventina usando diversos marcadores. En segundo lugar, analizamos su círculo social y lazos de parentesco, fijándonos con especial interés en el vínculo matrimonial que genera un excepcional caso de promoción social. Finalmente, estableceremos una comparación con otras dos mujeres hispanas que usamos como argumento añadido para proponer el estatus liberto de Faventina.

\section{Colonia Iulia Urbs Triumphalis Tarraco y los textos}

Capital de la provincia Hispania Citerior, puerto y centro comercial del Occidente romano, la Colonia Iulia Urbs Triumphalis Tarraco hunde sus raíces en un campamento militar (s. III aC) contiguo al oppidum ibérico Kesse (s. v aC) que servirá de base y puerto de entrada para controlar la vía Augusta o Heraclea en la Segunda Guerra Púnica. Este carácter militar se conservará durante las guerras celtibéricas, numantinas y lusitanas, hasta el s. III aC, cuando el campamento romano comienza a fusionarse con el núcleo ibérico, dando lugar a una entidad urbana que desarrolla ya una actividad civil y comercial significativa.

Al convertirse en capital de la provincia de Hispania Citerior, la ciudad se monumentaliza construyéndose dos foros, teatro, anfiteatro, circo intraurbano etc.; el peso como puerto comercial se acrecienta y se genera una gran estructura administrativa bajo gestión imperial, proceso ampliamente estudiado (Schulten, 1948; Alföldy, 1933, 2002, 2003; Arrayás, 2003; Dupré, 2004; Hauschild, 1983; Le Roux 1998; Mar 1993; Mar y Ruiz de Arbulo, 2011; Mar et al., 2012, 2017; Ruiz de Arbulo, 2000; Ruiz de Arbulo et al., 2012.).

Urbanización, comercio y gestión imperial generarán una importante masa de libertos; como fenómeno parejo y paralelo, la producción de epigrafía también aumentará, conservando hoy un riquísimo corpus que supera las mil quinientas inscripciones. En cuanto a la epigrafía servil, contamos con un amplio abanico de esclavos y libertos privados, públicos y un significativo número de miembros de la familia Caesaris, desde tabularii de la $X X$ hereditatum hasta una liberta de Ceionia Plautia, hermana de Lucio Vero (CIL II $\mathrm{I}^{2} / 14$, 1093).

En tanto que Panzram (2001: 75, 90) destaca la ingente información sobre la lealtad y fidelidad al emperador de los libertos tarraconenses, concordamos con Serrano Delgado (1988a: 113) en que la epigrafía de Tarraco es especialmente rica en lo que a datos familiares se refiere, en parte debido al magnífico conjunto de inscripciones funerarias reutilizadas en la necrópolis paleocristiana que no sufrieron una extrema descontextualización.

Pasemos entonces a analizar brevemente las inscripciones que presentan a Faventina, a la que debemos situar en época flavia, siguiendo las dataciones propuestas para todas las dedicaciones en el CIL $\mathrm{II}^{2} / 14$. 
El primer epígrafe es el $C I L \mathrm{II}^{2} / 14,1331$, actualmente perdido y del que solo conservamos el dibujo. ${ }^{1}$ Trasladado desde Tarragona a Guissona entre los siglos XV y XVI, posteriormente fue llevado a Lleida y tras este último movimiento se perdió. En dicho dibujo se reconoce un campo epigráfico delimitado por molduras rectas y dobles. El soporte y la carencia de fórmulas funerarias hacen que sea calificada en $C I L \mathrm{II}^{2} / 14$ como dedicación honorífica, aunque nada impide que pudiese pertenecer a un contexto funerario. Si bien en el esbozo observamos lo que parecen tres primeras líneas anepigráficas o ilegibles, son las tres últimas las que contienen la información sobre los individuos a analizar.

$$
\text { / - - - - / [- - -]lin+[- - -?] / Corn(elia) Faventina / matri }
$$

La primera línea legible contiene dudas de lectura, aunque se plantea la aparición de duonomina femeninos. Si bien en CIL $\mathrm{II}^{2} / 14$ se presenta como [---]lin+---], se interpreta como [---]line[---] o como variante de su dativo [---]lin(a)e (fig. 1).

Independientemente de la lectura de la letra incierta, creemos improbable la aparición de duonomina en esta línea. Analizando la onomástica contemplada en el CIL II ${ }^{2} / 14$ no encontramos ni un solo nomen que contenga la partícula -lin-. Podríamos proponer que correspondiese a una libertination abreviada, l(iberta), seguida de un cognomen que comenzase por in-. No obstante, en el corpus de Tarraco solo conservamos un cognomen que comience con dicha partícula, paradójicamente el cognomen Ingenua (CIL II $\left.{ }^{2} / 14,1019\right)$.

Sin embargo, la partícula -lin- es más frecuente en cognomina. Debido al incalculable número de cognomina existentes en la onomástica romana, nos hemos ceñido a los que contempla el $C I L \mathrm{II}^{2} / 14$ y hemos encontrado siete cognomina femeninos con dicha partícula. ${ }^{2}$ Por otra parte, en el dibujo, esta partícula aparece en el centro de la línea y el espacio para incluir un nomen, incluso abreviado, parece insuficiente, teniendo en cuenta además que esa partícula suele aparece como parte y no como inicio de un cognomen. La existencia de un nomen en la línea anterior, hoy perdida, pudiera ser factible, pero esa división es más frecuente en estructuras onomásticas masculinas, como sucede en CIL II ${ }^{2} / 14$, 1246; 1249; 1212. No obstante, en la onomástica femenina, menos extensa, esta separación es menos frecuente y, si tomamos como referencia a nuestra dedicante, esta se presenta siempre en una sola línea.

Así pues, siguiendo criterios onomásticos y la posible ordinatio del texto, podríamos estar ante un nombre único, pudiéndonos remitir a un probable estatus servil, pues con la aparición de un nombre único se suele asumir que el portador (Einnamig) es de condición esclava (Bruun, 2014: 608). Recalcamos que, pese a ser un importante marcador de estatus, no sería incontestable, pues por economía un ingenuus podría escoger citar únicamente

1. HEp 1, 1981, $450=E R L$ 16. El dibujo se atribuye a Pasqual (1768) No repetiremos que se trasladó junto con los comentados más adelante (C/L $\|^{2 / 14}$, 1246; 1249; 1212 y el ClL $\|^{2 / 14}$, 1334), sin relación aparente con las inscripciones tratadas en este artículo.

2. Gemellina ClL $\|^{2} / 14$, 1526; Ingenua, ClL $\|^{2} / 14$, 1019; Marcellina CIL $\|^{2} / 14$, 358; 1177; (Corn) Marullina CIL $\|^{2} / 14$, 1301; Omullina CIL I²/14, 106; Paulina CIL I²/14, 76a; 98; 699; 1477; Tertullina CIL $\|^{2} / 14,833 ; 1235 ; 1512$; Si tomamos la mayoritaria interpretación [---]line[---], cabe reseñar la existencia de una Haline C/L $\|^{2} / 14,1104$, hermana de vicarii imperiales del S.I. 


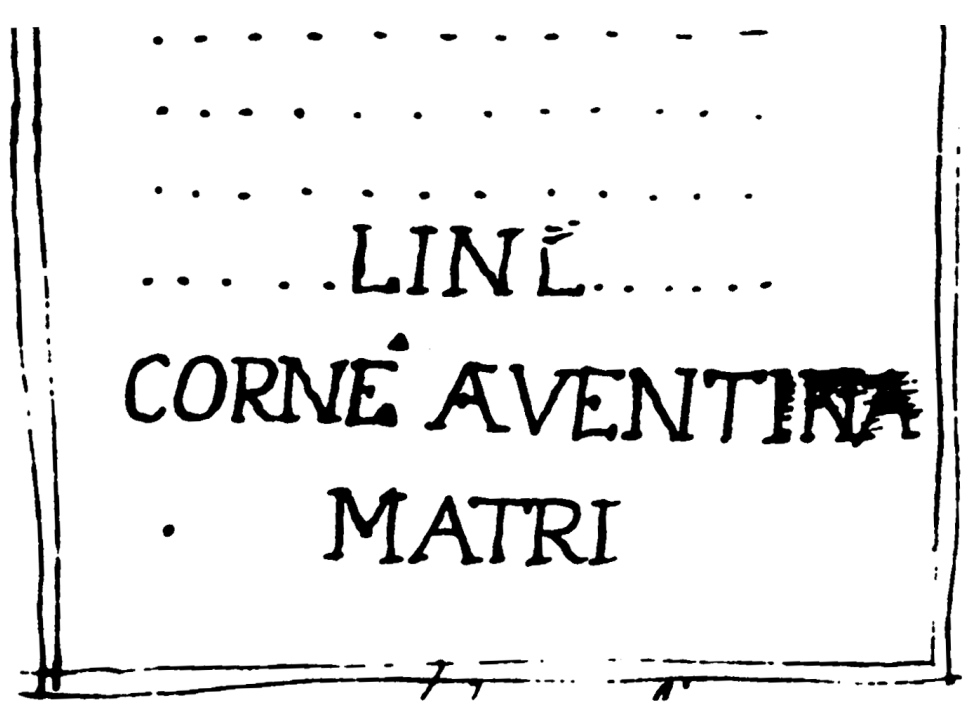

Figura 1. ClL $\|^{2} / 14,1212$; según $C / L \|^{2} / 14$ (cortesía de sus editores).

su cognomen. La dedicada es la madre de la dedicante, ya que en la alineación central de la última línea hallamos un matri que define el vínculo familiar.

Cierto es que, en algún momento de su vida, si no en su totalidad, esta mujer tuvo que ser necesariamente esclava, pues como veremos más adelante dio a luz a dos hijos libertos. Si concebimos la inscripción como funeraria y tomamos nuestra propuesta sobre su onomástica/estatus, su hija Faventina habría nacido forzosamente esclava, convirtiéndose en liberta en algún momento de su vida. Siendo conscientes de la precariedad del dibujo y de la incierta propuesta de lectura, para defender de manera sólida ese nacimiento esclavo, abordaremos más tarde otros marcadores.

La dedicante es Cornelia Faventina, individuo central de nuestro estudio, quien según la lectura del CIL II ${ }^{2} / 14$ aparece con el nomen abreviado Corn(elia). Si bien encontramos la abreviatura del nomen en los cuatro epígrafes dedicados por esta mujer, en este caso diferimos de la lectura del CIL $\mathrm{II}^{2} / 14$. Creemos factible la lectura de una posible ligadura de la -e- con una -l- que conformaría un Cornel(ia), pues también hallamos otra ligadura en el inicio del cognomen, con la unión de la -f- y la -a- de Faventina.

Nos encontramos, pues, ante una dedicación de descendiente a ascendiente, siendo estas más infrecuentes que en sentido inverso, todavía más cuando los progenitores son/ fueron de estatus servil. ${ }^{3}$

3. En Tarraco, en referencia a individuos de estatus servil o incerti con altas probabilidades de serlo, encontramos seis dedicadas como mater y diez dedicados como pater conmemorados por sus descendientes de manera unilateral. No hallamos ninguna dedicación conjunta a ambos progenitores. Encontramos además a individuos de cierto prestigio, apareciendo dos seviri (C/L $\left.\|^{2} / 14,1238 ; 1243\right)$, un liberto imperial tabellarius $\left(C / L \|^{2} / 14,1095\right)$ y un heredero y liberto de, posiblemente, un liberto imperial $\left(C / L \|^{2 / 14}, 1280\right)$ 
Tras la dedicación a su madre, hallamos dos epígrafes dedicados a dos hermanos suyos. Son dos inscripciones gemelas en cuanto a formulación y disposición del texto, con la única variación del cognomen del dedicado.

El CIL II ${ }^{2} / 14,1249=$ CIL II $4454=H E p ~ 1,1989,432$ y $434=I R C$ II, 8 (tít. original) y 10 (tít. nuevo) $=\operatorname{ILER} 5567=E R L 48=\mathrm{Nr}$./Inv. Museu de Guissona 3/465, se conserva en el Museo de Guissona tras su traslado y reutilización. Es una basa de estatua opistógrafa con el mismo texto y ordenación en ambas caras. El epígrafe original se inscribe dentro de un cimacio lésbico, mientras el texto posterior lo hace dentro de molduras triples y rectas.

\section{M(arco) Cornelio / Phaedimo / seviro / Corn(elia) Faventina / fratri}

La dedicación sin fórmulas de apertura ni cierre es clasificada en CIL $\mathrm{II}^{2} / 14$ como honorífica. Cabe comentar que dos excepcionalidades de estas dedicaciones son: el carácter honorífico y que la dedicante no pertenece al círculo esposa-hijos (Barrón de la Cuesta, 2014: 178) ni a relaciones no sanguíneas, dependencia, etc. (Barrón de la Cuesta, 2017: 378; 2018: 47) siendo estas las más comunes en dedicaciones a seviri. En este caso, el dedicado aparece con tria nomina y cognomen griego, Phaedimus; ${ }^{4} \mathrm{y}$ al igual que acontece frecuentemente con seviri y augustales*, el individuo carece de libertination (Duthoy, 1970: 91). Cabe recordar, oponiéndonos a Flory (1984: 218), que la ocultación del estatus liberto es frecuente mediante la omisión de la libertination y que dicha ocultación puede llevar incluso a la omisión del propio cargo de augustal o sevir (Melchor Gil, 2003: 137-138). La paridad en cuanto a la aparición en Tarraco de seviri y augustales* (Duthoy, 1978) es absoluta. Encontramos quince casos de seviri, sevir, VIviralis, seviratus, etc. y diecisiete en los que acompañan a dicho término partículas como augustorum, augustalis, etc., por lo que, aunque no se especifique que sean seviri augustales, creemos que siguiendo esta tendencia son prácticamente identificables como libertos, pese a carecer de libertination.

Tras la información onomástica, el individuo aparece denominado como sevir en una línea reservada para dicho honor. Subsiguientemente, la dedicante se presenta con un Corn(elia) abreviado y su cognomen íntegro. Finalmente, la última línea se reserva para una denominación, fratri, aunque sin ningún tipo de epíteto, ni afectivo ni honorífico, al igual que acontece en la dedicación a su progenitora.

El mismo esquema encontramos en la inscripción $C I L \mathrm{II}^{2} / 14,1246=$ CIL II $4453=$ HEp 1, 1989, 431 = IRC II, 7 y $12=$ ILER $5566=$ ERL 47 = Nr./Inv. Museu de Guissona 3/446. De características similares, en este caso nos encontramos ante una basa de estatua no opistógrafa con un campo epigráfico delimitado con molduras triples y rectas.

M(arco) Cornelio / Faventino / seviro / Corn(elia) Faventina / fratri

4. Solin (1982: 523-524). Dicho cognomen es analizado como parte de «Nombres del mundo de los dioses y del mundo mitológico. Héroes y heroínas". Solin (1990: 81) defiende que los nombres de dioses y héroes serían infrecuentes en ingenui y libres de origen griego, siendo más propios de esclavos. Sobre el uso de cognomina griegos, seguimos a Ross Taylor (1961), Bruun (2013) o George (2005: 23-24). 
La formulación y disposición es absolutamente idéntica. La dedicación honorífica comienza con la aparición del praenomen (Salway, 1994: 13, 133) y la diferencia recae en el cognomen Faventinus, de origen latino. Le siguen el cargo de sevir; la dedicante, presentada una vez más con un Corn(elia) abreviado y su cognomen desarrollado y, finalmente, el fratri sin epíteto alguno.

Lo más interesante de la inscripción es la homonimia entre el hermano y la hermana, que en distinto género portan el mismo cognomen Faventinus/Faventina, pudiendo servirnos como marcador para identificar a Faventina como liberta. Aunque los cognomina latinos tienen menor incidencia en la población servil, ${ }^{5}$ y una posibilidad sería que ella hubiese nacido después de una manumisión materna, pese a carecer de libertination, consideramos que dos marcadores nos indican lo contrario.

Como nuestra propuesta de identificación de la madre de Faventina como esclava en CIL II ${ }^{2} / 14,1331$ no es sólida de manera aislada, creemos consistente y aclaratoria la relación onomástica entre los hermanos. La práctica de nombrar a vernae y hermanos con homonimias o derivaciones de los nombres de sus progenitores era frecuente. De hecho, Solin (1990: 81-82) propone que dicha práctica fuese una innovación romana originada en un estrato superior e intelectual. Además, siguiendo a Bruun, la incidencia de cognomina de origen latino sería considerablemente mayor en los vernae, equiparándose en porcentaje latinos/griegos para favorecer así su promoción social. ${ }^{6}$

Podemos observar esos porcentajes parejos en los cognomina de ambos hermanos, Phaedimus y Faventinus, por otra parte muy similares fonéticamente. De hecho, siguiendo a Solin (1990: 66-67), los casos de nombres de hermanos ligados a través de similitudes fonéticas y no solo semánticas son muy frecuentes: CIL VI 25429 Rhode/Rhodope, CIL VI 8434 Rhodo/Rhodinus, o en Plin. Epist. 3, 1, 7, Thelxis/Chelys, etc. Sería más probable que Faventina fuese ingenua, si encontrásemos a hermanos con nombres diferentes al de ella, pero en nuestro caso su cognomen la vincula claramente a un hermano liberto y no sigue la tendencia a desligarse de prácticas onomásticas serviles en descendientes de libertos (Bruun, 2013: 24-25, 28-29). No podemos descartar incluso la posibilidad de que fuesen gemelos, ya que en Roma solo conservamos quince casos explícitos de gemelos. Desgraciadamente solo podemos acudir a nombres como Geminus, Gemellus, Hierus, Asylus, etc. o, como en este caso, nombres pares para identificarlos (Solin, 1990: 65-66). En resumen, sería improbable que, tras una posible manumisión del progenitor, se eligiese un cognomen para la hija ingenua que la vinculase a un hermano nacido en esclavitud. De ahí que no nos convenza la propuesta de Navarro Caballero (2017, 601-602) sobre la posibilidad de que fuese, incluso, hija de liberto (M. Cornelius ---), sumado al hecho de que sus hermanos fuesen seviri.

5. (Bruun, 2013: 22). Recopilación de tablas de porcentajes sobre el origen de los cognomina de esclavos en CIL VI. Destaca Solin (2001: 309) aportando cifras como $67 \%$ de cognomina griegos, 31,2 \% latinos y 1,8\% de cognomina «bárbaros».

6. Bruun (2013: 112-113) coteja los cognomina de vernae con los números de Solin (1971) sobre la ciudad de Roma (43,3\% griegos y 56,7 \% latinos) y los de Hermann-Otto (1994) sobre los vernae privados de Roma (45\% griegos y $55 \%$ latinos). 
Por tanto, sería altamente factible que Faventinus, nacido en esclavitud — pues alrededor de tres cuartas partes de los esclavos habrían nacido esclavos mediante el slave breeding (Bradley, 1992: 210-214, 220-221), con una ratio mayor en provincias (Scheidel, 1997: 163, 166-167) - fuese nombrado con un cognomen latino para favorecer su promoción social (algo que ha conseguido) y que, por tanto, su hermana homónima hubiese nacido asimismo en esclavitud. ${ }^{7}$

Por otra parte, el estudio mismo del cognomen Faventinus/a es esclarecedor, facilitándonos otro marcador más. El sufijo -inus/a, difundido en época imperial, se asemeja en significado al de -anus/a. En la distribución por sexos, en el sufijo -anus/a la ratio masculino/ femenino es del 72 \%-28 \%, mientras que en -inus/a es del 62 \%-38 \% (Kajanto, 1982: 36). Sobre los cognomina rematados en -anus/a e -inus/a existen dos posibles orígenes.

En primer lugar, el origen patronímico proveniente de la derivación de cognomina y nomina (Flavius/Flavinus). El sufijo -anus/a comenzó a usarse en la tardorrepública de modo poco común entre las élites, tanto en adopciones como para crear dobles cognomina, en ocasiones surgidos de segundas nupcias (Kajanto, 1982: 32-33, 113-114). En época imperial la tendencia muda hacia la derivación del nomen materno. Por tanto, por norma general, los cognomina derivados de nomina son infrecuentes en esclavos.

Derivado de los cognomina paternos (no del nomen) y de apelativos simples, el sufijo -anus/a es habitual en la plebs ingenua, ${ }^{8}$ cayendo en desuso en las élites. Asimismo, Kajanto (1982: 113) propone que también se utiliza para derivar nombres de divinidades con la connotación de pertenencia (Martinus, Minervius, Saturninus, etc.), algo que, pese a no ser comentado en su texto, era frecuente en esclavos y libertos (Solin, 1990: 81). Por otra parte, Kajanto (1982: 34) defiende que esclavos, libertos públicos e imperiales, cuyos cognomina rematasen en -anus/a, pudieran haber sido anteriormente esclavos privados, formando su cognomen del nomen (e incluso cognomen) de su amo.

En segundo lugar, el origen geográfico es patente a través de sufijos relacionados con ciudades que acaban en -nt/-entia (Pollentia, Fidentia, Florentia, Valentia). En el sustrato latino

7. Aunque todavía se debate sobre significados alternativos del término verna (Chester G. Starr, 1942; Crespo Ortiz de Zárate, 2003), sería prácticamente incontestable la aparición de dicha denominación. En Tarraco solo tenemos tres casos. CIL $\|^{2} / 14,1097$ : un Augusti nostri verna encargado de la XX hereditatium; CIL $\|^{2} / 14$, 1278: un esclavo explícito cuyo verna vienensis se interpreta en el corpus como su lugar de nacimiento, y CIL II2/14, 1305, con un incertuus con duonomina identificado como v(erna) Leptitan(us). Su aparición es infrecuente en general (Rawson, 1992: 172), pese a ser considerados aparentemente de mayor valor. Además, el término se concentra en el s. ॥ tras el uso masivo en la familia Caesaris (Weaver, 1997: 21). Según Bruun (2013: 26) en el CIL VI solo se conservan seiscientas inscripciones con el significado claro de "esclavo nacido en casa". Hermann-Otto (1994: 413) y Bruun (2013: 27) exponen que el término servus-verna no es utilizado para esclavos privados mayores de 25 años. Exceptuando los casos de esclavos imperiales, sería muy improbable usar el término en adultos. Por tanto, si se considera demasiado arriesgada la hipótesis del nacimiento esclavo, nuestra tesis es igualmente aplicable si tomamos la opción de la compra conjunta de madre e hijos, siendo usualmente «renombrados» en dicho momento.

8. Kajanto (1982: 103), en su tabla 24, considera que, del total de sufijos terminados en -inus/a de época imperial, un $3,5 \%$ es portado por senadores; un 85\%, por libres (sin precisar incerti/ingenui) y un 2,5 \%, por libertos. Kajanto (1968: 521-522) sí explica sus criterios onomásticos para considerar individuos incerti/ingenui. Considera que los incerti cuyos padres lleven nomen cuentan con una prueba de ciudadanía ingenua. Estamos en total desacuerdo con dicho criterio. Además, estas cifras no son aplicables a nuestro caso, ya que remiten al patronímico y no a la geografía. 
parten de sus participios de presente (pollens, fidens, florens, valens) (Kajanto, 1982: 116) y en el sustrato celta, forman adjetivos (Albertos Firmat, 1966: 291-292), siendo ambos tipos de uso frecuente.

Si bien más del 50 \% de los cognomina acabados en -inus/a pertenecen al conjunto Flavinus, Martinus y Silvinus (derivaciones de cognomina) y Antonius, en nuestro caso Faventinus/a deriva claramente de Favens/Faventia, por lo que debemos vincularlo a un contexto geográfico.

Kajanto (1982: 46) propondrá el vínculo de ciertos cognomina con los diferentes epítetos de coloniae, como es el caso de Romulensia (CIL II 1059), vinculándolo a la Colonia Iulia Romula Hispalis, e incluso de nomina, como Pollentius, aparentemente relacionado con los esclavos de la colonia Iulia Pola Pollentia Herculanea (CIL V 213).

En la Aemilia encontramos una Faventia (hoy Faenza), antiguo asentamiento etrusco (Faoentia). Asimismo, cercana a Tarraco encontramos también una Faventia, la Colonia Iulia Augusta Paterna Faventia Barcino (Plin. Nat. Hist 3, 13) "Colonia Barcino cognomine Faventia». Los apelativos Iulia y Augusta se relacionan con su fundación, Faventia habría sido tomado del municipio itálico y Paterna estaría relacionado con epítetos de otras colonias, como la Colonia Iulia Paterna Arelate Sextanorum o la Colonia Iulia Paterna Claudia Decumanorum Narbo Martius (Balil, 1964).

Por tanto, independientemente del origen del sufijo, su aparición en esclavos públicos e imperiales, su utilización en la derivación de nombres de divinidades y apelativos simples, y su uso en derivaciones geográficas y vínculos con coloniae, como es nuestro caso, hacen que el sufijo -inus, y por tanto Faventinus/a, fuese común en población servil y no exclusivo de la plebs ingenua. De hecho, Solin (1990: 81) comenta que los nombres con derivaciones de elementos míticos y divinos, características físicas y sobre todo geográficas, son más frecuentes en la onomástica esclava, ya que el ingenuus no podía incorporarlo a la tradición familiar. Concordamos con el argumento, ya que domo, origo o natio muestran el origen geográfico en el caso de que un ingenuus quisiese recalcarlo.

Para conocer más datos sobre este cognomen, llevamos a cabo una búsqueda a través del banco de datos epigráficos EDCS, puesto que es inviable para nuestro estudio hacer manualmente un vaciado exhaustivo de todas las Faventinae de la epigrafía romana. ${ }^{9}$

Observamos que el número de apariciones es bajísimo, con tan solo 45 registros. Solamente 42 de ellos son válidos, pues uno constituye una mención incorrecta del epíteto de Barcino (CIL II 412) y hay dos duplicidades de las inscripciones de nuestro artículo, posiblemente fruto del periplo de las piezas y la característica opistógrafa de (CIL $\left.\mathrm{II}^{2} / 14,1249\right)$.

De esas 42 apariciones, 20 se dan en Italia (47,6 \%); otras 11, en Hispania (26,2\%), y 11 , en el resto de provincias (26,2\%). Curiosamente en Aemilia solo encontramos tres casos $(7,1 \%)$, mientras que Hispania aporta 10 en la Citerior y una en la Bética, el mismo número de casos que el resto de provincias en su conjunto. Cabe comentar, además, que

9. Consulta de 2 de enero de 2019, búsqueda digital presentada a modo de aproximación a dicho cognomen. 
en la Citerior tenemos a las únicas tres Faventinae con más de una aparición epigráfica: Cornelia Faventina en Tarraco; Porcia Faventina, en «Los Bañales» (AE 2014, 702; 703; 704), y Valeria Faventina, en Tarraco/Barcino (CIL II 4591; CIL II ${ }^{2}$ 14, 989).

Así pues, nos encontramos ante una realidad sorprendente. El nombre del municipio Faventia de la Aemilia es introducido en la nomenclatura de la colonia Barcino, ciudad vecina a Tarraco y uno de los puertos preeminentes de Hispania Citerior. Su influencia será tal que el número de apariciones de dicho cognomen superará en Hispania las apariciones de las Faventinae en Aemilia.

Todavía más importante para nuestro trabajo es el estatus jurídico de aquellas mujeres que portan dicho cognomen. Hemos separado libres, incertae, libertas y esclavas. Aclaramos que los criterios seguidos para calificar a una incerta no se basan en la omisión de la filiación/libertination, ya que de las 36 mujeres tan solo Valeria Faventina en Barcino, porta filiación (CIL II 4591). Nos basamos en la coincidencia del nomen con el cónyuge CIL IX 1839; (CIL XIII 5107), con descendientes (CIL VI 24484, CIL III 4112) o incongruencias como ser heres, pero aportar solo el cognomen (CIL III 4116) etc.

Las conclusiones que cabe extraer difieren absolutamente de lo expuesto por Kajanto (1982: 196), quien aporta 27 mujeres (sin especificar certi/incerti) y una esclava/liberta para la totalidad del CIL. Las cifras encontradas grosso modo nos facilitan 8 libres $(22,3 \%), 17$ incertae $(47,3 \%), 8$ libertas $(22,3 \%)$ y 3 esclavas $(8,4 \%)$ del total de 36 mujeres. Si las analizásemos de manera binaria, entre mujeres libres y mujeres con explícita o probable pátina servil, nos encontraríamos ante una proporción del 22,3\% frente al $78 \% .^{10}$

Por tanto, con todos estos condicionantes expuestos, sería todavía más improbable que se eligiese dicho cognomen para distinguirla de un nacido en esclavitud.

Retomamos entonces los puntos en los que nos basamos para, a través de estos tres epígrafes, defender el estatus jurídico liberto de Cornelia Faventina.

En primer lugar, la propuesta de que su madre portase nombre único, remitiéndonos a un estatus servil; en segundo lugar, la explícita relación con sus dos hermanos, ambos seviri y, por tanto, de una altísima probabilidad de estatus liberto; en tercer lugar, la homonimia con un hermano, que la vincularía muy probablemente a un nacimiento/origen esclavo; finalmente y en cuarto lugar, el mismo origen y uso de su cognomen.

Para concluir el análisis epigráfico estudiaremos la dedicación honorífica $C I L \mathrm{II}^{2} / 14$, $1212=$ CIL II $584=H E p$ 1, 1989, $449=$ IRC II, $13=I L E R 5527=$ ERL 2. Trasladada junto

10. En cuanto al cognomen masculino, los datos de Solin (1988, 77: r. 524, 330 r. 45, 113, 196, 468) difieren de Ios hallados en EDCS (consulta: 24 de abril de 2019). Acotando Hispania, contamos con 16 ejemplos: cuatro en la Bética y 12, en la Citerior. Siguiendo los criterios utilizados anteriormente encontramos: cinco ingenui (31\%), siete incerti (44\%), un liberto (6\%), un servus Augustorum, (CIL II $/ 5,727)(6 \%)$ y dos plurales simples «Faventini» (13\%), resultando por tanto un $56 \%$ de casos con individuos de cierta o probable extracción servil. Cabe destacar que ocho de ellos se encuentran en la zona de influencia de Barcino, habiendo cuatro Faventini en Tarraco (CIL $\left.\|^{2} / 14,927 ; 1292 ; 1246 ; 1678\right)$, un homónimo de la citada Valeria Faventina en Barcino (IRC IV, 222), un incertuus de altísima probabilidad de extracción liberta en lluro (IRC I, 220), un ingenuus en Aeso (C/L II 4468) y uno de los plurales en Lesera (CIL II2/14, 780). 
con los epígrafes comentados, esta permaneció en Lleida y actualmente se encuentra en el Instituto de Estudios Ilerdenses. Encontramos otra basa de estatua que comparte con CIL $\mathrm{II}^{2} / 14,1249$ la decoración con cimacio lésbico.

T(iberio) Manlio / Ti(beri) f(ilio) Gal(eria) / Silvano aed(ili) / II vir(o) flam(ini) / Corn(elia) Faventina / uxor

Una vez más, sin fórmulas de apertura ni cierre, encontramos la dedicación a un individuo que muestra, esta vez sí, la estructura onomástica completa de un ingenuus con praenomen, nomen, filiación, tribu y cognomen (fig. 2).

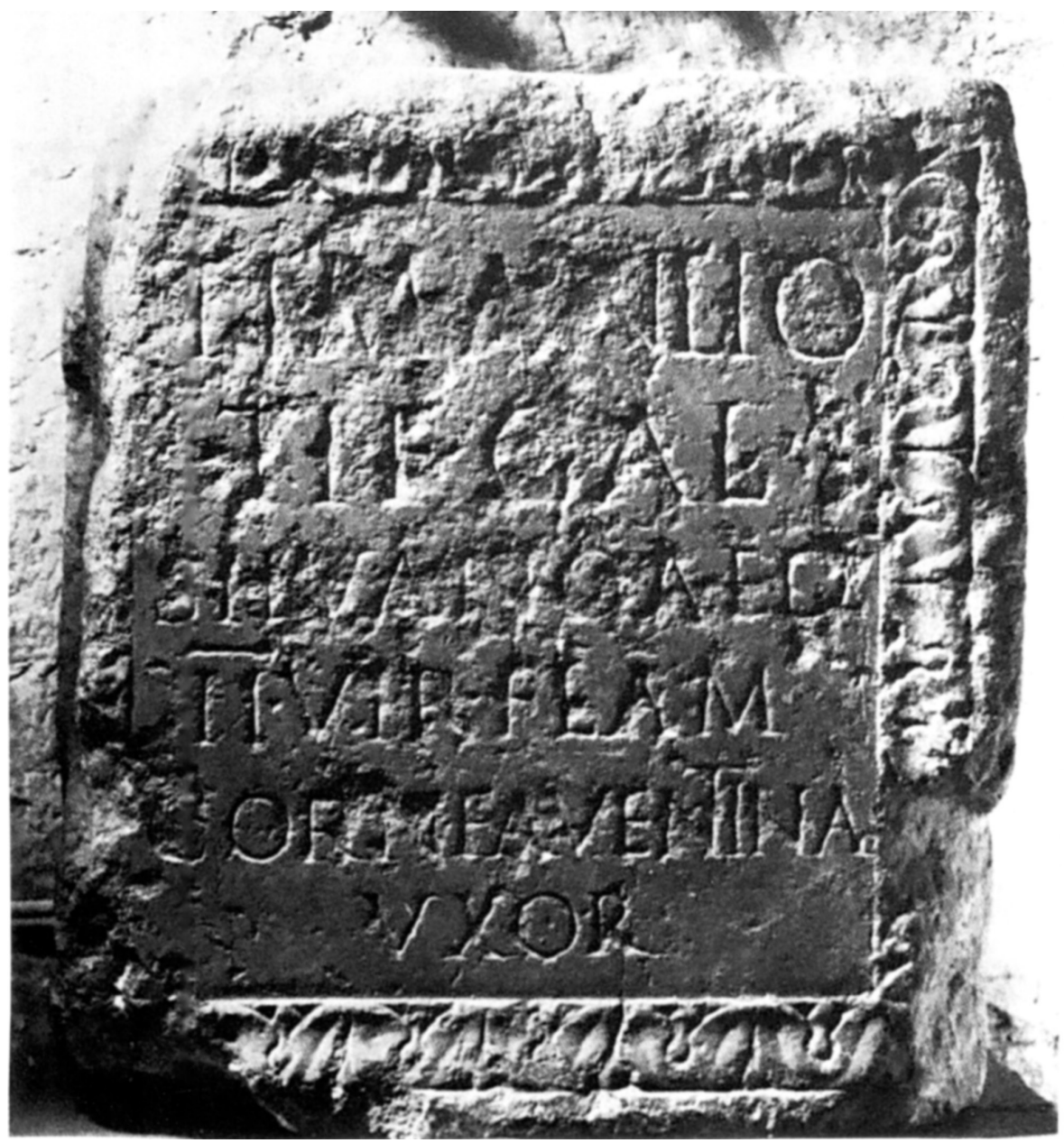

Figura 2. ClL $\|^{2} / 14,1331$; según $C l L \|^{2} / 14$ (cortesía de sus editores). 
Tras dicha estructura onomástica, encontramos los cargos del cursus honorum municipal de este individuo, que fue edil, duovir y flamen. Por tanto, es un individuo de la élite municipal perteneciente, como duovir, al ordo decurionum de la colonia que, aunque no se especifique que sea Tarraco, es lo más probable, pues su estatua se erigió allí. Además, Galeria es la tribu más frecuente en Tarraco, lo que se ha puesto en relación con el probable origen augusteo de la fundación colonial (Amela Valverde, 2015).

Tras los cargos, hallamos otra vez a la dedicante, presentada de igual manera, con nomen abreviado y cognomen desarrollado. Lo más interesante en esta inscripción es que en la última línea, reservada para la denominación, no denomina al dedicado como en el caso de sus hermanos y madre, sino que se autodenomina como uxor. Esta elección le confiere un mayor peso en la inscripción, invirtiendo la tendencia a la denominación del dedicado, en una pieza que refiere a un varón (Flory 1984: 216) y, además, de alto prestigio social. Por otra parte, la autodenominación uxor, nos remite a un matrimonio legítimo entre la liberta y un individuo de la élite municipal.

\section{Movilidad social y matrimonio para la liberta romana}

Si bien la movilidad social de los libertos varones desde época tardorrepublicana se conseguía a través del progreso profesional y económico (Garnsey 1981: 365-367), nos es sumamente difícil acercarnos a la movilidad social de las libertas. A través de la epigrafía, la aparición de las profesiones de las mujeres es infrecuente. Por ejemplo, un caso único es el de cuatro libertas de diferentes patronos que regentan una culina en Ostia ( $A E 1975$. 197; 1980. 216) que ha sido relacionado con el culto erótico a Venus Encyna debido a esta excepcionalidad (Kleijwegt, 2001: 120). En su mayoría, las profesiones femeninas se relacionan con la venta de productos alimenticios, la industria textil y la hostelería (Pardo Torrentes, 2014: 255-257, 260-262, 263-265). Los epígrafes de los columbaria muestran claramente el desconocimiento que tenemos sobre las profesiones de libres, libertas y esclavas, puesto que sus ocupaciones son recordadas en un porcentaje ínfimo en comparación con las de los varones. Por ejemplo, Treggiari (1975: 395) propone que el «trabajo» por excelencia de las esclavas sería la procreación, siguiendo los patrones de conmemoración del columbarium de los Statilii, donde se especifica el trabajo de 157 esclavos frente al de 20 mujeres. Para el de Livia, la ratio es 61:18. Borbonus (2014: 123) defiende que el hecho de que las inscripciones especifiquen relaciones familiares más frecuentemente en mujeres $(26 \%)$ que en hombres ( $17 \%$ ) se vincula con esa "profesión familiar» femenina frente al trabajo masculino. En Tarraco no conservamos ni un solo ejemplo de profesiones ejercidas por esclavas ni libertas. ${ }^{11}$

11. Domínguez Arranz y Gregorio Navarro (2014: 239) proponen para C/L $\|^{2} / 14,1436$ la aparición de una esclava nutrix o similar, creemos sin suficiente apoyo. Para libertas, en solo un epígrafe configurado como diálogo, 
Por tanto, ¿cuáles eran las posibilidades reales de promoción social para una liberta? En este caso, es evidente que el matrimonio fue clave para su movilidad social. Cabría preguntarse si su círculo familiar, con dos hermanos seviri verosímilmente libertos (Serrano, 1988b), fue el que la catapultó fuera de la endogamia familiar que caracteriza el matrimonio liberto (entendiendo por endogamia el matrimonio entre miembros de la misma familia servil) o, si fue a la inversa; es decir, si utilizó este matrimonio para beneficiar a su familia sanguínea como hace de manera evidente en las inscripciones.

El matrimonio entre colliberti, marcado siempre por las tempranas uniones propiciadas por los propietarios para la reproducción de vernae (Varr. Re. Rust. I, 17, 5), así como aquel entre libertos de diferentes familias, es predominante en la epigrafía servil. Las uniones con ingenui son menos frecuentes, y aquellas que conectan a una liberta con un miembro de los ordines superiores son excepcionales (McGinn, 2004: 206-207).

De entre todos los libertos de Tarraco, Cornelia Faventina es la persona que consigue una mayor promoción social a través del matrimonio. Encontramos matrimonios de colliberti, como los paradigmáticos casos de listas de colliberti, como CIL II ${ }^{2} / 14,1245 ; 1252 ; 1265$; 1483 ; 1487; 1581; 1617; 1620b. También libertos casados fuera de la gens, pero mayormente con libertas, o como mucho con incertae. Por ejemplo, ningún liberto imperial ${ }^{12}$ ni sevir augustal, los libertos más prestigiosos de la comunidad, aparece unido en matrimonio con una ingenua que porte explícitamente su filiación. ${ }^{13}$ También hallamos libertos casados con libertas propias, ${ }^{14}$ pues el matrimonio entre patronos y libertas propias, siendo más frecuente en el estrato servil, podía ser beneficioso para los primeros, que sumaban los derechos de esposo y patrono. Sin embargo, ellas tenían derechos y obligaciones dobles y paradójicas, como poder iniciar un divorcio sin consentimiento del patrono (Wacke, 1989, 425-426), a la vez que la lex Iulia les prohibía unirse en conubium con una nueva pareja (Perry, 2014: 22-23). Por otra parte, si bien los matrimonios entre ingenui y liberta aliena eran legales y fueron reforzados a través de las leges Iulia y Papia (Dio. Cass. 54.16.2) para estimular la descendencia legítima (D. 23.2.44) y equilibrar la falta de mujeres en los ordines superiores (excluyendo al rango senatorial), estos eran socialmente censurables.

CIL $\|^{2} / 14,1682$, se ha propuesto la prostitución como profesión. Los ejemplos en varones también son escasos: dos aurigas $C / L \|^{2} / 14$, 1281; 1285; un educator $C I L \|^{2} / 14$, 1277; un médico $C / L \|^{2} / 14$ 1280; un plumbarius, incertuus posiblemente liberto $C / L \|^{2} / 14,1276$; un inaurator $C / L \|^{2} / 14,1278$; un aerarius $C / L \|^{2 / 14}, 1279$ y un dispensator CIL II/14, 1550. Como complemento, introducimos las inscripciones CIL II/14, 2082-2083; 2084, títulos en cañerías de officinae regentadas por libertos. Omitimos los cargos ejercidos por esclavos y libertos imperiales, cuya aparición sí es frecuente.

12. Weaver (1992: 156) expone que 139 de las 276 esposas de caes. servi y 336 de 758 esposas de aug. liberti no portan nomina imperiales. Por tanto, el $42 \%$ de esos matrimonios supera la barrera de la familia Caesaris con mujeres bien ingenuae bien libertae, apuntando a una promoción social mayor.

13. Para Mangas (1971: 258-261), los libertos públicos gozarían de una consideración similar a la de los imperiales. El único liberto público conservado en Tarraco (CIL I²/14, 1199), liberto de provincia (sin especificar cuál), está unido a una mujer sin libertination, pero con cognomen griego, a la que se refiere como contubernalis. Por tanto, tampoco hay rastro de matrimonio con una ingenua.

14. La denominación liberta et uxor aparece en $\mathrm{ClL} \|^{2} / 14,1254$, esposa de un sevir Tarraconensis; 1266 , esposa de un magister larum; 1349, esposa de un incertuus, y 1622, esposa de un incertuus con cognomen oriental. La expresión sive liberta sive uxor también aparece en el título CIL I²/14, 1682. 
En este caso, pues, no encontramos a un individuo casado con su propia liberta, ya que no comparten nomen, sino que Faventina habría sido manumitida por un tercero. Faventina rompe la norma en una práctica universal dentro del Imperio, el matrimonio de individuos de extracción servil que se unen mayoritariamente con individuos de su mismo estatus, ya sea en la endogamia de la gens o con libertos de otras familias. Por ejemplo, el $40 \%$ de las sepulcrales del CIL VI que presentan matrimonios muestran matrimonios de individuos con el mismo nomen (Ross Taylor, 1961: 113-132).

La liberta podía conseguir, a través del matrimonio, mayor promoción socioeconómica que el liberto, cuyo progreso se basará siempre en su carrera profesional, pues las posibilidades de emparentar con mujeres de mayor estatus son prácticamente inexistentes. El matrimonio "exogámico», que supera la barrera de la jerarquía social al que una liberta podría optar, les estaba tácitamente vetado por la mentalidad romana a aquellos libertos varones que podían progresar precisamente en todo aquello que a las libertas no les era permitido. Lo que por sexo les estaba vetado a ellos, les era permitido a ellas y viceversa. Por ejemplo, las manumisiones matrimonii causa no eran aplicables a esclavos/ libertos respecto a su dueña (Gai. Inst. I, 19, 39; Dig. 40, 2, 9, 13). ${ }^{15}$ Concordamos en esta idea con Serrano, si bien los ejemplos epigráficos de libertas casadas con hombres de la élite son escasos, siendo más comunes los de magistrados municipales ingenui de origen servil casados con libertas (Serrano, 1988a: 202-203). En Hispania la mayoría de casos de libertos casados con ingenuae se dan en puertos o ciudades comerciales (Serrano, 1988a: 112-116); por ejemplo, CIL II 4534; 724 o HAE, 439.

Por tanto, la esfera privada y familiar va a ser la herramienta más eficaz para la promoción pública y social de las libertas. Esto nos replantea incluso las posibilidades de promoción social en comparación con las ingenuae, ya que con el apoyo de un patrono benefactor podrían dar un mayor salto que ingenuae del común, sin capacidad a priori de relacionarse con las élites de la comunidad.

El patrono debía dar consentimiento a la liberta para llevar a cabo el matrimonio, pudiendo usar a la liberta como intermediaria, si le facilitaba peso socioeconómico o político. ${ }^{16}$ Otra

15. (Cf. Treggiari, 1971: 198). Los matrimonios entre ingenui y libertas eran más comunes cuanto más bajo era el estrato social. Weaver (1972: 179-195) establece que, mientras los matrimonios de libertos con ingenuae suponen tan solo un 15\%, los de libertas con ingenui ascienden al 38\%. Evans-Grubbs (1993: 129) comenta que los matrimonios mejor aceptados entre libertos y patronas se producen entre antiguos coesclavos, donde la mujer logra la manumisión con anterioridad. La posibilidad de ser manumitidas antes que sus parejas era frecuente y puede deberse a un sistema de ahorro conjunto (Treggiari, 1976: 92); a la búsqueda de hijos ingenui, aunque ilegítimos (Flory, 1984: 218), y sobre todo (López Barja, 2007, 55-57) a su menor precio y posible reducción del mismo al dejar hijos en esclavitud, pues de hecho Columela $(1,8,19)$ aconseja liberar a la esclava que haya tenido más de tres hijos. Para Rawson (1992: 180-181), los esclavos varones, tanto privados como imperiales, tardaban más en ser manumitidos.

16. Kleijwegt (2001: 117-118) defiende que tras las reformas claudianas del 51 (Gai. Inst. 1.32; Ulp. Frag. 3.6), que concedían beneficios a aquellos/as que construyesen barcos para la annona, el ius trium liberorum a libertas sin necesidad de engendrar cuatro hijos (Suet. Claud. 19), las reformas directamente lanzadas hacia las mujeres como la liberación de la tutela, la capacidad de disposición de sus propiedades sin supervisión (Gai. Inst. 3.44) y la posibilidad de testar sin consentimiento de su patrono, etc., pudieran deberse a la existencia de libertas con grandes fortunas y, por consiguiente, a la búsqueda por parte del emperador de que se uniesen como propietarias al sector comercial. 
posibilidad es que esta situación se diese con mayor frecuencia en libertas sin patrono que pudiesen casarse sin pedir consentimiento. De hecho, en el caso de Faventina, la ausencia epigráfica de su patrono nos hace replantearnos la intervención del mismo en su ascenso social y/o su movilidad al margen de este, pudiendo deberse incluso a su fallecimiento.

Cornelia Faventina aparecerá siempre en una posición de poder económico indudable, siendo la dedicante de las cuatro inscripciones. No tenemos en Tarraco ningún individuo que la supere en apariciones como dedicante, si bien es interesante comentar que en Hispania hay un mayor índice de dedicantes mujeres, generando un 1:1 de ratio entre dedicantes mujeres y hombres (Saller y Shaw, 1984: 138-139). Asimismo, especialmente como hijas y madres, tienen una mayor probabilidad de ser dedicadas (Edmondson, 2005: 204-206). Por otra parte, su voluntad, agente y no impuesta, parece evidente sin fórmulas tipo ex testamento fecit/faciendum/posuit, testamento (fieri) iussit/curavit, etc.

\section{La comparación con Fulvia Celera y Acilia Plecusa}

Para entender el peso socioeconómico que esta mujer transmite a través de sus dedicaciones, comentaremos brevemente dos casos excepcionales de mujeres de contextos sociales diametralmente diferentes en los que el matrimonio aparece como vínculo básico en su círculo de poder.

El primer ejemplo nos mantiene en Tarraco, también en época flavia. Encontramos a una notable dentro de la sociedad municipal, Fulvia Celera, quien actúa como dedicante encargando un epígrafe honorífico a su madre, flamínica de la colonia de Tarraco. ${ }^{17}$ Aparece como dedicada en otras dos inscripciones honoríficas, una realizada por uno de sus libertos y la segunda llevada a cabo por otros dos libertos que hacen explícito que es ex testamento; definiéndola como flaminica perpetua coloniae Tarraconensium y flaminica provinciae Hispaniae Citerioris. ${ }^{18}$ Finalmente, aparece en una dedicación honorífica dispuesta ex testamento por dos libertos y herederos de Celera a Caius Vibius Latronus, su «esposo», con varios puestos en la curia municipal y provincial. ${ }^{19}$

17. (CIL I²/14, 1224) Popiliae M(arci) f(iliae) / Secundae / flaminic(ae) / col(oniae) Tarrac(onensium) / Fulvia Celera / matri optimae.

18. (CIL I²/14, 1221) Fulviae / M(arci) f(iliae) / Celerae / flam(inicae) perpet(uae) / Concor(diae) Aug(ustae) / Fulvius / Diadochus / lib(ertus) / patronae y (CIL II2/14, 1179) Fulviae M(arci) f(iliae) / Celerae / flaminicae / perpetuae / col(oniae) Tarrac(onensium) / et flaminicae / p(rovinciae) H(ispaniae) c(iterioris) ex / testamento ipsius / Fulvius Musaeus et / Fulvius Moschus / liberti. Para la importancia de sus libertos como círculo de poder: Schulze-Oben (1989: 216-217). Sobre la importancia de su «triple» flaminado: Mirón Pérez (2000: 41-43) y Gregorio Navarro (2013: 215-217; 2014: 23-26; 2016: 123-135).

19. (CIL I2/14, 1172) C(aio) Vibio C(ai) f(ilio) / Gal(eria) Latroni / q(uaestori) Ilvir(o) item / Ilvir(o) quinq(nennali) / col(oniae) Tarrac(onensium) / flam(ini) p(rovinciae) H(ispaniae) c(iterioris) ex / testament(o) Fulviae / Celerae heredes / Fulvius Musaeus / et Fulvius Moschus. Este es a su vez hijo de un quattorvir del municipio de Sigarra (CIL II 4479) y de lunia Severina (C/L II 4480). Pese a que en el mundo académico se da por sentado que este individuo es su esposo, no hay rastro de denominaciones tales como maritus, coniux, uxor, etc. de ahí nuestra utilización del entrecomillado. 
Encontramos diferencias con Cornelia Faventina, pues en este "matrimonio" no se muestra ningún tipo de movilidad social, sino una "endogamia» dentro de las clases privilegiadas, ya que Fulvia Celera es ingenua e ilustre de nacimiento. ${ }^{20} \mathrm{Su}$ aparición no es siempre agente, buscando visibilidad social, sino que encontramos disposiciones testamentarias que recuerdan la figura de una mujer con prestigio suficientemente conocido en vida.

Sin embargo, encontramos importantes similitudes: todas las dedicaciones son basas de estatuas de gran tamaño, carecen de epítetos honoríficos o afectivos, están relacionadas con hombres (exceptuando las dedicaciones de ambas a sus madres), se limitan al círculo familiar, y no encontramos dedicaciones evergéticas o apoyo por parte del ordo municipal. ${ }^{21}$

Cabría introducir la posibilidad de un fenómeno típicamente liberto: la imitación de la cultura epigráfica de las élites y en este caso del ciclo estatuario de Celera (Navarro Caballero, 2003: 123-124). Es decir, que, desde una posición menor, pero unida en matrimonio a un individuo de esa misma élite municipal, Faventina tratase de reproducir con ciertas diferencias, no solo la acción de dedicar, sino la misma tipología de los monumentos para integrarse en la comunidad. ${ }^{22}$

El apoyo municipal sí se dará en todas las dedicaciones de Acilia Plecusa, quien nos traslada a la Singilia Barba de la Bética del s. II dC (Ordóñez Agulla, 1988; Atencia Páez, 1988). Caso excepcional en el que nos encontramos ante una liberta casada con su propio patrono, M. Acilius Fronto, del ordo equester. ${ }^{23}$ Aparece en nueve dedicaciones singilenses, tanto como agente como miembro de referencia familiar. ${ }^{24}$

20. Seguimos a McGinn (2004: 206-207) y, por tanto nos posicionamos en contra de las visiones de Mirón Pérez (1996: 276) y de Gregorio Navarro (2014: 24).

21. Contr. Mirón Pérez (1996: 193) y Gregorio Navarro (2013: 219), quienes defienden la actividad evergética de Celera. La epigrafía no sostiene dicha tesis, pues son dedicaciones honoríficas dentro del marco familiar que ni siquiera cuentan con el apoyo del ordo de la colonia.

22. Sobre la imitación liberta de la representación de las élites y el trickle-down effect: Borg (2012: 40-41) y sobre la imitación del ordo equester a través de la figura de Trimalción: Bodel (1999: 42-43). Siguiendo a Verboven (2011: 89-90), la búsqueda de visibilidad epigráfica por parte de los libertos no pretende una integración en las élites, sino que representaría una competitividad entre los mismos libertos. Sobre la "creación a través de la imitación" en la epigrafía: Andreau (1991: 220-221).

23. Acilia Plecusa es la única liberta casada con un eques de manera explícita en toda Hispania. En Cic. Pro. Sest. 110 encontramos la crítica al eques L. Gellius Poplicola, quien «supuestamente» se había casado con una liberta. Sobre la asimetría de las uniones patrono-liberta/patrona-liberto: de las setecientas inscripciones analizadas por Weaver (1992: 153-155) se deriva una de ratio 9:1, ya que las segundas serían incluso calificadas como odiosae (Cod. lust. 5.4.3) y, presuntamente (Evans-Grubbs: 1993, 129), prohibidas por Septimio Severo (Dig. 23.2.13). Pese a que los matrimonios con libertae suae son promovidos por las leyes augusteas, siendo incluso una de las exenciones en la lex Aelia Sentia (Gai. Inst. 1.18-19), para un patrono era más respetable mantener a su liberta en concubinato que hacerla su esposa (Dig. 25. 7. 1.). Sin embargo, no debemos confundir el concubinato con la poligamia, pues el matrimonio romano es monógamo en esencia (Rawson, 1974: 288). Su posición era similar a la de una esposa (Paul. Sent. 2.20.1; Dig. 32.49.4), pero con una asimetría de estatus.

24. Con «miembro de referencia familiar» nos referimos a dos inscripciones en las que dos nietos de Plecusa son identificados como nietos de ella y no de su abuelo, lo cual es extraordinario, no solo por la importancia de la línea paterna, en este caso del ordo equester, sino por el estatus liberto de Plecusa. CIL II2/5, 802 M(anio) Acilio Frontoni / Sing(iliensi) Barb(ensi) nepoti / Aciliae Plecusae; ClL I²/5, 803 Aciliae Sedatae / Septuminae / Sing(iliensi) Barb(ensi) nep/ti Aciliae Plecusae. 
Actuará como dedicante en siete ocasiones: a su esposo, ${ }^{25}$ a su hijo, ${ }^{26}$ a su hija ${ }^{27}$ y a tres amici, (dos al procurator vegetianum, ${ }^{28}$ a la esposa de este, ${ }^{29}$ y una última a un amigo ${ }^{30}$ cuyo nombre desconocemos ${ }^{31}$ ).

Las tres mujeres comparten el carácter honorífico de las dedicaciones, la dedicación a sus respectivos esposos o la curiosa ausencia de epítetos de ningún tipo; ni afectivos, típicos de la epigrafía funeraria, ni honoríficos, exceptuando la dedicación de Celera a su madre como mater optima. Puede que responda a una voluntad de separarse de los usos funerarios de las capas más humildes, plagados de epítetos afectivos. Sin embargo, las similitudes entre Faventina y Plecusa son considerablemente más numerosas:

1) Su compartido estatus jurídico; ambas son libertas, una explícitamente y otra, bajo nuestra propuesta.

2) El matrimonio; clave en su promoción social saltando la barrera del estatus jurídico. Mientras la herramienta que catapulta a Plecusa desde la esclavitud hasta la activa interacción pública con los ordines superiores es el matrimonio con su propio patrono del ordo ecuestre, ${ }^{32}$ la movilidad social de Faventina al contraer matrimonio con

25. CIL II2/5, 784 M(anio) Acil(io) Quir(ina) Frontoni Sing(iliensi) Barb(ensi) prae/f(ecto) fabrum d(ecreto) d(ecurionum) / m(unicipum) m(unicipii) Sing(iliensis) Barb(ensis) Acil(ia) Plecusa patrono et / marito honore accep(to) imp(ensam) remis(it).

26. CIL I²/5, 795 M(anio) Acilio Phlegonti / Sing(iliensi) Barb(ensi) / Acilia Plecusa mater / d(edit) d(edicavit) / huic ordo sanctis/simus Sing(iliensis) Barb(ensis) / ornamenta decu/rionalia decrevit. Sobre el estatus de su hijo: Rawson (1989: 30-31), Weaver (1992: 147-148), Mirón (2005: 293), Bruun (2013: 31) y Cidoncha (2018: 377-378), y la ausencia de su sevirato: Pons Sala (1977).

27. CIL I²/5, 796 Acil(iae) Mani f(iliae) Sept(uminae) Sing(iliensi) Barb(ensi) / d(ecreto) d(ecurionum) / m(unicipum) m(unicipii) Sing(iliensis) Barb(ensis) Acil(ia) Plecusa / mater honore / accep(to) imp(ensam) remis(it).

28. ClL II/5, 780 P(ublio) Magnio Q(uinti) f(ilio) Quir(ina) Rufo / Magoniano tr(ibuno) mil(itum) IIII / proc(uratori) Aug(usti) XX her(editatium) per Hisp(aniam) Baet(icam) / et Lusitan(iam) item proc(uratori) Aug(usti) / per Baetic(am) ad kal(endarium) Veget(ianum) / item proc(uratori) Aug(usti) prov(inciae) Baet(icae) ad / ducen(a) Acili(a) Plec(usa) amico optimo / et bene de provincia / semper merito d(onum) d(edit); ClL I²/5, 781 [P(ublio) Magnio Q(uinti)] f(ilio) Quir(ina) Rufo / [Magonia]no tr(ibuno) mil(itum) IIII / [proc(uratori) Aug(usti) X]X her(editatium) per Hisp(aniam) Baet(icam) / [et Lusitan(iam) i]tem proc(uratori) Aug(usti) / [per Baetic(am) ad kal(endarium) Veget(ianum) / [item proc(uratori) A]ug(usti) prov(inciae) Baet(icae) ad / [ducen(a) Acil(ia) P]lec(usa) amico optim[o / et bene] de provincia I [semper me]rito d(onum) d(edit).

29. CIL II2/5, 782 Carviliae P(ubli) f(iliae) Censonill(ae) Magni / Rufi proc(uratoris) Aug(usti) XX her(editatium) per Hisp(aniam) / Baet(icam) et Lusitan(iam) item proc(uratoris) Aug(usti) / per Baet(icam) ad kal(endarium) Vegetian(um) item / pr[o]c(uratoris) / Aug(usti) prov(inciae) Baet(icae) ad ducen(a) / Ac[il(ia) Plec(usa)] / amicae op[timae d(onum) $d$ (edit)]. Su relación con ambos individuos se ha vinculado a los posibles intereses comerciales de los Acilii, asociados a la producción y exportación de aceite.

30. HEp 8, 1998, 353 Acil(ia) Plec(usa) amico.

31. Acilia Plecusa tiene una sola aparición como dedicada en una inscripción funeraria de la necrópolis de las Maravillas en Bobadilla (Málaga), que se ha vinculado a una posible villa de los Acilii (Romero Pérez, 1993/94; Romero Pérez y Vargas Vázquez, 2017). CIL II2/5, 830 D(is) M(anibus) s(acrum) / Acilia Plae/cusa Sing/[il(iensis) B]arbensis / [ann(orum) - - - h(ic)] s(ita) e(st). Para la infrecuente tipología de este enterramiento en Hispania: Borbonus (2014: 146-147).

32. Rodríguez Neila (1981: 43) propone la idea de «urgencia matrimonial» con libertae suae para evitar la «extinción» de un nomen, incluso dentro de los ordines superiores. Además, desde la legislación augustea los incentivos para contraer matrimonio situaban a aquellos hombres que permaneciesen solteros en una posición social y económicamente desventajosa (Treggiari, 1991: 84). Pudiendo ser este el caso de Plecusa, no es aplicable al de Faventina. Aunque en el corpus de Tarraco solo encontramos a 10 Manlii, de diferentes cronologías, Faventina no es liberta de su esposo. Sobre dicha «urgencia» y la diferencia generacional en el matrimonio: McGinn (2004: 206). 
un notable externo a su nomen no debe ser infravalorada debido a su excepcionalidad. Mirón Pérez (2005: 295-296) propone que una pronta viudedad pudiera haber favorecido que Plecusa adquiriese una mayor presencia en la comunidad, y no sería descabellado que este fuese también el estado de Faventina, quien no presenta además descendientes ni herederos.

3) Las ausencias; como la carencia de dedicaciones honoríficas hacia su persona, de dedicaciones ex testamento o simplemente de descendientes (Faventina) o libertos (ambas), símbolo claro de poder socioeconómico que limita nuestro conocimiento sobre el legado real que tuvieron en las colonias, pues la aparición de esclavos y libertos propios puede interpretarse como la muestra de la independencia legal y económica de la esposa durante el Alto Imperio (Edmondson, 2001: 337). Kleijwegt (2001: 111) afirma que sería arriesgado considerar a Plecusa como una "mujer influyente» dentro de Singilia Barba, inclinándose por el carácter propagandístico. Estos elementos sí los encontramos en Celera, quien convierte en herederos a sus libertos, puede que ante la ausencia de descendientes naturales y la concepción de estos como "filii sine natura» (Mouritsen, 2011 : 38-40). ${ }^{33}$ De hecho, la aparición de hijos facilitaría el conocimiento del estatus de Faventina, pues si estos fuesen esclavos/libertos, la madre tendría que haberlos concebido necesariamente en esclavitud.

4) La búsqueda agente de la visibilidad social y familiar; pues su aparición como dedicantes sí nos acerca a una voluntad propagandística. No obstante, esa publicidad es absolutamente inversa en la presentación del matrimonio. Plecusa no oculta su onomástica y denomina a su esposo como patronus et maritus, dándole peso y agradecimiento a su marido por la promoción social facilitada. Por el contrario, Faventina omite u oculta su onomástica completa/liberta y se autodenomina uxor. De esta manera, consciente o no, le resta peso y agradecimiento a su marido, aunque no patrono. Es relevante per se, pero también porque, en cambio, invierte esta tendencia denominando a sus familiares sanguíneos en el resto de inscripciones.

\section{Conclusiones}

Nuestro objetivo principal era definir el estatus jurídico liberto de Cornelia Faventina. Es este estatus lo que hace realmente atractiva la promoción adquirida a través de su matrimonio, algo olvidado en la historiografía y que hemos querido resaltar.

Por tanto, para proponer su estatus jurídico nos basamos en: la hipótesis que presentamos sobre la onomástica materna (aportando una nueva lectura), la aparición de dos

33. El poder de Celera se extrae de la capacidad de dejar disposiciones testamentarias y de que terceros, en este caso sus libertos, dediquen a/en su nombre, si bien en la onomástica de estos no hay rastro de libertination ni la clásica libertination a Gaia. Si bien es cierto que su uso se concentra en torno al Principado (Keegan, 2011: 163-164), sí hallamos numerosos casos en Tarraco. 
hermanos seviros, la homonimia del cognomen con uno de ellos, el análisis del cognomen mismo, el uso que hace de la onomástica — denominando a su esposo con la estructura completa, mientras ella omite toda partícula que remita a cualquier estatus-y la constante aparición como dedicante con clara voluntad propagandística.

Además, como argumento complementario y como un séptimo marcador añadido, analizamos las notables características que comparte con Acilia Plecusa, pese a hallarse en provincias colindantes y separadas cronológicamente por casi un siglo. El peso del estatus es tal que compartirán mayor cantidad de características de la epigrafía liberta que usos cronológicos o geográficos.

Así, ambas se presentan como potentes mujeres dedicantes en la búsqueda agente de la movilidad y visibilidad social, demostrando su poder económico y promoción social. Esta promoción en ambas se vincula directamente con la excepcional ruptura de la norma tácita de las uniones matrimoniales de los libertos, casados con individuos de su propio estatus, presentándonos matrimonios que superan la barrera de su estatus y la jerarquía social; Plecusa, con su patrono del ordo equester, y Faventina, con un ingenuus de la élite municipal externo a su nomen, lo que evidencia una movilidad social comparable a la de Plecusa, porque, pese a no ser un eques, su esposo no pertenecía a su familia.

En especial, es sumamente interesante la aparición de vínculos o lazos de familia extensa, cuya presencia es menos común frente a la tríada padre-madre-hijo (Cic. Off. 1. 53-54), y que nos hablan de la importancia de la familia en ambos contextos, importancia sumamente marcada en los epígrafes de libertos. De hecho, concordamos con George (2005: 39-40), quien compara la dedicación familiar liberta con la honorífica como sinónimo de participación en la vida pública a través del símil entre la res publica y la unidad familiar. Recordemos que los vínculos familiares más básicos —o la «muerte social» de Patterson (1982) o Bodel y Scheidel (2016)— son cercenados en esclavitud, y en toda la epigrafía liberta la aparición de la familia y la exhibición de los vínculos familiares es constante. Esa búsqueda de la promoción y visibilidad de Faventina se ciñe a la publicidad del campo privado con dedicaciones a su familia. Tanto en Faventina como en Plecusa observamos que, cuanta mayor promoción social consiguieron, más se preocuparon en ampliar tanto el número de dedicaciones como la cantidad de relaciones no nucleares (Rawson, 1992: 7-8), pues de manera habitual las dedicaciones de libertos se concentran en la familia y, sobre todo, en dedicaciones matrimoniales (Edmondson, 2005: 213-214) y Faventina y Plecusa superan esa barrera dedicando a sus fratri y amici.

Cornelia Faventina ejemplifica al liberto promocionado que busca la asimilación a las élites (reproduciendo modelos similares a los de Fulvia Celera), pero compartiendo usos típicamente libertos como la búsqueda constante de visibilidad social y familiar (como Acilia Plecusa).

Por tanto, Cornelia Faventina constituye un caso excepcional de movilidad social, femenina y liberta dentro de la sociedad romana, y debido a su singularidad ha de ser distinguida dentro del patrón matrimonial romano liberto en Hispania. 


\section{Agradecimientos}

Este texto se encuadra dentro del proyecto de investigación Latinos Junianos: definición e identificación epigráfica, Ministerio de Economía y Competitividad (HAR2017-86523-P).

\section{Abreviaturas}

CIL II: Corpus Inscriptionum Latinarum II: Inscriptiones Hispaniae Latinae, Berlín, 1869-1892.

CIL $\mathrm{II}^{2}$ /5: Corpus Inscriptionum Latinarum $\mathrm{II}^{2}$ : Inscriptiones Hispaniae Latinae, editio altera, pars 5. Conventus Astigitanus, Berlín - Nueva York, 1998.

CIL $\mathrm{II}^{2}$ / 14: Corpus Inscriptionum Latinarum $\mathrm{II}^{2}$ : Inscriptiones Hispaniae Latinae, editio altera, pars 14. Conventus Tarraconensis, Berlín - Nueva York, 1995-2012.

CIL III: Corpus Inscriptionum Latinarum III: Inscriptiones Asiae, provinciarum Europae Graecarum, Illyrici Latinae, Berlín, 1873-1902.

CIL V: Corpus Inscriptionum Latinarum V: Inscriptiones Galliae Cisalpinae Latinae, Berlín, 18721877.

CIL VI: Corpus Inscriptionum Latinarum VI: Inscriptiones urbis Romae Latinae, Berlín, 18761989.

CIL IX: Corpus Inscriptionum Latinarum IX: Inscriptiones Calabriae, Apuliae, Samnii, Sabinorum, Piceni Latinae, Berlín, 1883.

CIL XIII: Corpus Inscriptionum Latinarum XIII: Inscriptiones trium Galliarum et Germaniarum Latinae, Berlín, 1899-1943.

ERL: F. LARA PEINADO, Epigrafía romana de Lérida, Lleida, 1973.

HAE: Hispania Antiqua Epigraphica, Suplemento anual de Archivo Español de Arqueología. Instituto de Arqueología y Prehistoria «Rodrigo Caro», Consejo Superior de Investigaciones Científicas, Madrid.

HEp: Hispania Epigraphica, Archivo Epigráfico de Hispania, Universidad Complutense, Madrid.

ILER: J. VIVES, Inscripciones latinas de la España romana, Barcelona, 1971-1972.

IRC II: G. FABRE, M. MAYER e I. RODÀ, Inscriptions romaines de Catalogne II, Lérida, París, 1985. 


\section{Bibliografía}

ALBERTOS FIRMAT, M. L., 1966, La Onomástica personal primitiva de Hispania: Tarraconense y Bética Instituto Antonio de Nebrija, Salamanca.

ALFÖLDY, G., 1993, Tarraco y la Hispania romana, cultos y sociedad, en M. MAYER OLIVÉ y J. GÓMEZ PALLARÈS (eds.), Religio Deorum Actas del Coloquio Internacional de epigrafía, culto y sociedad en Occidente, Tarragona, 1992, Ausa, Sabadell, 7-26.

ALFÖLDY, G., 2002, Desde el nacimiento hasta el apogeo de la cultura epigráfica en Tarraco, en L. HERNÁNDEZ GUERRA, L. SAGREDO SAN EUSTAQUIO y J. M. SAINZ SOLANA (eds.), Actas del I Congreso Internacional "La historia antigua hace 2000 años», Valladolid, 2000, Valladolid, 61-74.

ALFÖLDY, G., 2003, Sociedad y epigrafía en Tarraco, en S. ARMANI, B. HURLET-MARTINEAU y A. STYLOW (eds.), Epigrafía y sociedad en Hispania durante el Alto Imperio, estructuras y relaciones sociales, Madrid/Alcalá de Henares, 2000, Alcalá de Henares, 159-176.

ÁLVAREZ PÉREZ, A., GARCÍA-ENTERO, V., GUTIÉRREZ GARCÍA-MORENO, A. Y RODÀ DE LLANZA, I. (coords.), 2009, El marmor de Tarraco. Explotació, utilització $i$ comercialització de la pedra de Santa Tecla en època romana, Institut Català d'Arqueologia Clàssica, Hic et nunc 6, Tarragona.

AMELA VALVERDE, L., 2015, Tarraco

Tardorrepublicana, Hispania Antiqua 39, 47-70.

ANDREAU, J., 1991, El liberto, en A. GIARDINA (ed.), El hombre romano, Alianza Editorial, Madrid, 201-225.

ARRAYÁS, I., 2003, El territorium de Tarraco en època tardo-republicana romana (ss. III-I a. C.). Poblament i estructures rurals al Camp de Tarragona, Butlletí Arqueològic 25, 25-55.

ATENCIA PAEZ, R., 1988, La ciudad romana de Singilia Barba (Antequera, Málaga), Servicio de Publicaciones de la Diputación de Málaga, Málaga.

BALIL ILLANA, A., 1964, Colonia Iulia Augusta Paterna Faventia Barcino, Instituto Español de Arqueología, Madrid.
BARRÓN DE LA CUESTA, A., 2014, Ciudadanía y sevirato augustal: el ejemplo de Aquae Sectiae (Gallia Narbonensis), Antesteria 3, 171-188.

BARRÓN DE LA CUESTA, A., 2017, La representación epigráfica de la relación filial en el caso de los seviri Augustales, en J. M. IGLESIAS GIL y A. RUIZ-GUTIÉRREZ (eds.), Monumenta et memoria. Estudios de epigrafía romana, Edizioni Quasar, Roma, 373-387.

BARRÓN DE LA CUESTA, A., 2018, Contribución al estudio de la movilidad geográfica en la Gallia Narbonensis. El caso de los seuiri Augustales, Latomus $77,1,26-58$

BODEL, J., 1999, The Cena Trimalchionis, en H. HOFMANN (ed.), Latin Fiction. The Latin Novel in Context, Routledge, Londres, 38-51.

BODEL, J. y SCHEIDEL, W., 2016, On Human Bondage: After Slavery and Social Death, Wiley-Blackwell, Oxford.

BORBONUS, D., 2014, Columbarium tombs and collective identity in Augustan Rome, Cambridge University Press, Cambridge.

BORG, B., 2012, The Face of the Social Climber: Roman Freedmen and Elite Ideology, en S. BELL y T. RAMSBY (eds.), Free At Last! The Impact of Freed Slaves on the Roman Empire, Bristol Classical Press, Londres, 25-49.

BRADLEY, K., 1992, Wet-nursing at Rome: A Study in Social Relations, en B. RAWSON (ed.), The family on ancient Rome: new perspectives, Routledge, Londres, 201-229.

BRUUN, C., 2013, Greek or Latin? The owner's choice of names of vernae in Rome, en M. GEORGE (ed.), Roman Slavery and Material Culture, University of Toronto Press, Toronto, 19-42.

BRUUN, C., 2014, Slaves and freed Slaves, en C. BRUUN y J. EDMONSON (eds.), The Oxford Handbook of Epigraphy, Oxford University Press, Oxford. 
CIDONCHA, F., 2018, Libertae et coniuges: las uniones entre libertas y patronos en el imperio romano, en P. PAVÓN (ed.), Marginación y mujer en el Imperio romano, Edizioni Quasar, Roma.

CRESPO ORTIZ DE ZÁRATE, S., 2003, Verna en Hispania romana, Libros Pórtico, Valladolid.

DOMÍNGUEZ ARRANZ, A. y GREGORIO NAVARRO, M. C., 2014, Serva hic sita est. Las esclavas de Tarraco a través de la epigrafía funeraria, en A. DUPLÁ ANSUATEGUI, M. V. ESCRIBANO PAÑO, L. SANCHO ROCHER Y M. A. VILLACAMPA RUBIO (eds.), Miscelánea de Estudios en homenaje a Guillermo Fatás Cabeza, Institución Fernando el Católico, Zaragoza, 237-243.

DUPRÉ, X. (ed.), 2004, Tarragona. Colonia Iulia Urbs Triumphalis Tarraco, Las capitales provinciales de Hispania 3, L'Erma di Bretschneider, Roma.

DUTHOY, R., 1970, Notes Onomastiques sur les *Augustales cognomina et indication de statut, L'Antiquité Classique 39, 88-99.

DUTHOY, R., 1978, Les Augustales, ANRW/Aufstieg und Niedergang der römischen Welt 6, 2, 1254-1309.

EDCS, Epigraphik-Datenbank Clauss / Slaby, ed. M. Clauss, Katholische Universität EichstättIngolstadt (en línea).

EDMONDSON, J., 2005, Family Relations in Roman Lusitania: Social Change in a Roman Province?, en M. GEORGE (ed.) The Roman Family in the Empire, Oxford University Press, Oxford, 183-229.

EDMONDSON, J., 2011, Slavery and the Roman Family, en K. BRADLEY y C. PAUL (eds.) The Cambridge World History of Slavery 1, Cambridge University Press, Cambridge, 356-361.

EVAN-GRUUBS, J., 1993, Marriage more shameful than Adultery: Slave Mistress Relationships, Mixed Marriages and Late Roman Law, Phoenix 47, 2, 125-154.

FLORY, M., 1984, Where Women Precede Men: Factors Influencing the Order of Names in Roman Epitaphs, Classical Journal 79, 3, 216-224.

GARNSEY, P., 1981, Independent Freedmen and the Economy of the Roman Italy under the Principate, Klio 63, 359-371.
GEORGE, M., 2005, Family Imagery and Family Values in Roman Italy, en M. GEORGE (ed.), The Roman Family in the Empire: Rome, Italy and Beyond, Oxford University Press, Oxford, 37-66.

GREGORIO NAVARRO, M. C., 2013, Fulvia Celera: el poder desde el sacerdocio, en DOMÍNGUEZ ARRANZ, M. A. (ed.), Política y género en la propaganda en la antigüedad: Antecedentes $y$ legado, Ediciones Trea, Gijón, 205-224.

GREGORIO NAVARRO, M. C., 2014, Rellegint la història. Les dones de Tarraco a través dels seus epitafis, Auriga. Revista de divulgació $i$ debat del món clàssic 71, 23-26.

GREGORIO NAVARRO, M. C., 2016, In honorem mulierum: conociendo a las mujeres de Tarraco a través de sus epitafios, Saldvie 16, 123-135.

GUTIÉRREZ, A., 2009, Les pedreres de Tàrraco, en F. TARRATS BOU (ed.), Tàrraco. Pedra a pedra, Exposició, Museu Nacional Arqueològic de Tarragona, Tarragona.

HAUSCHILD, T., 1983, Arquitectura romana de Tarragona, Publicacions de l'Excm. Ajuntament de Tarragona, Tarragona.

HERNÁNDEZ, L., 2006, Las libertas en Hispania. Manifestaciones epigráficas en la provincia Tarraconense, Hispania Antiqua 30, 119-142.

HERNÁNDEZ, L., 2013, Los libertos de la Hispania romana: situación jurídica, promoción social y modos de vida, Ediciones Universidad de Salamanca, Salamanca.

HERNÁNDEZ, L., 2016, Inscripciones de libertos hispanos, Ediciones Universidad de Valladolid, Valladolid.

KAJANTO, I., 1968, The Significance of Non-Latin Cognomina, Latomus 27, 517-534.

KAJANTO, I., 1982, The Latin cognomina, Giorgio Bretschneider, Roma.

KEEGAN, P., 2011, Roman Gaiae and the Discourse of Patronage: Retrogade C in CIL VI, en J. BODEL y N. DIMITROVA (eds.), Ancient Document and their Contexts. First North American Congress of Greek and Latin Epigraphy (2011), Brill, Leiden-Boston, 152-173. 
KLEIJWEGT, M., 2001, The social identity of Roman freedmen: probing the religious evidence, ARYS/Antigüedad Religiones y Sociedades 4, 181-196.

KLEIJWEGT, M., 2012, Deciphering Freedwomen in the Roman Empire, en S. BELL y T. RAMSBY (eds.), Free at last: The impact of freed Slaves on the Roman Empire, Bristol Classical Press, Londres, 110-129.

LE ROUX, P., 1998, Ejército y sociedad en la Tarraco romana, Butlletí Arqueològic 19-20, 83-107.

LÓPEZ BARJA DE QUIROGA, P., 2007, Historia de la manumisión en Roma: de los orígenes a los Severos, Publicaciones de la Universidad Complutense de Madrid, Madrid.

MANGAS, J., 1971, Esclavos y libertos en la España romana, Universidad de Salamanca, Salamanca.

MAR, R., 1993, Perspectives de Tarraco. La reconstrucció dels monuments de la capital provincial, Tarragona.

MAR, R. y RUIZ DE ARBULO, J., 2011, Tarragona romana. República i Alt Imperi (anys 218 a. C265 d. C), en Història de Tarragona 1, 205-538.

MAR, R., RUIZ DE ARBULO, J., GRIS, F., BELTRÁN-CABALLERO, J. A. y VIVÓ, D. (eds.), 2017, Herederos de Tarraco. Tarragona Patrimonio Mundial. Una nueva visión, Arola Eds., Tarragona.

McGINN, T. A. J., 2004, Missing Females? Augustus' Encouragement of Marriage between Freeborn Males and Freedwomen, Historia 53, 2, 200-208.

MELCHOR GIL, E., 2003, Indicaciones y omisiones del rango personal de los dedicantes en los homenajes estatuarios realizados en los municipios y colonias hispano-romanos, Saldvie: Estudios de prehistoria y arqueología 3, 129-141.

MIRÓN PÉREZ, D., 1996, Mujeres, religión y poder: el culto imperial en el Occidente mediterráneo, Universidad de Granada e Instituto de Estudios de la Mujer, Granada.

MIRÓN PÉREZ, D., 2000a, Fulvia Celera, en C. MARTÍNEZ, R. PASTOR, M. J. DE LA PASCUA Y S. TAVERA (eds.), Mujeres en la historia de España. Enciclopedia bibliográfica, Planeta, Madrid, 41-43.
MIRÓN PÉREZ, D., 2000b, Plecusa, Acilia, en C. MARTÍNEZ, R. PASTOR, M. J. DE LA PASCUA y S. TAVERA (eds.), Mujeres en la historia de España. Enciclopedia bibliográfica, Planeta, Madrid, 471-474.

MIRÓN PÉREZ, D., 2005, Matrimonio y promoción social de las esclavas en la Bética: el caso de Acilia Plecusa, en L. HERNÁNDEZ GUERRA (coord.), La Hispania de los Antoninos (98180). Actas del II Congreso Internacional de Historia Antigua, Valladolid, 291-304.

MOURITSEN, H., 2011, The Freedman in the Roman world, Cambridge University Press, Cambridge.

NAVARRO CABALLERO, M., 2003, Mujer de notable: representación y poder en las ciudades de la Hispania imperial, en S. ARMANI,

A. U. STYLOW y B. HURLET-MARTINEAU (coords.), Epigrafía y sociedad durante el Alto Imperio: estructuras y relaciones sociales. Actas de la mesa redonda organizada por la Casa de Velázquez, el Centro CIL II de la Universidad de Alcalá y L'Année Épigraphique (Madrid-Alcalá de Henares, 2000), Madrid, 119-127.

NAVARRO CABALLERO, M., 2017, Perfectissima femina. Femmes de l'élite dans l'Hispanie romaine, (Scripta Antiqua), Ausonius, Burdeos.

ORDÓÑEZ AGULLA, S., 1988, Cuestiones en torno a Singilia Barba, Habis 18-19, 319-344.

PANZRAM, S., 2002, Stadtbild und Elite: Tarraco, Corduba und Augusta Emerita zwischen Republik und Spätantike, Historia Einzelschriften 161, Franz Steiner Verlag, Stuttgart.

PARDO TORRENTES, S., 2014 Feminae frente al negotium: Mujer y comercio en la Roma Altoimperial, en P.D. CONESA NAVARRO, J. J. MARTÍNEZ GARCÍA, C. M. SÁNCHEZ MONDÉJAR, C. MOLINA VALERO Y L. GARCÍA CARRERAS (coords.), Antigüedad in progress. Actas del I Congreso Internacional de Jóvenes Investigadores del Mundo Antiguo (CIJIMA I), CEPOAT, Murcia, 249-268.

PATTERSON, O., 1982, Slavery and Social Death: a comparative study, Harvard University Press, Londres. 
PERRY, M., 2014, Gender, manumission and the Roman freedwoman, Cambridge University, Nueva York.

PONS SALA, J., 1977, Algunas consideraciones teóricas sobre el sevirato como indicador de dinamismo socio-económico, Memorias de Historia Antigua 1, 215-219.

RAWSON, B., 1974, Concubinage and other de Facto Marriages, TAPhA/Transactions of the American Philological Association 104, 279-305.

RAWSON, B., 1989, Spurii and the Roman View of Illegitimacy, Antichthon 23, 10-41.

RAWSON, B., 1992, Children in the Roman Family, en B. RAWSON (ed.), The family on ancient Rome: new perspectives, Croom Helm, Londres.

RAWSON, B. Y WEAVER, P. (eds.), 1997, The Roman Family in Italy: Status, Sentiment, Space, Clarendon Press, Oxford.

RODÀ DE LLANZA, I., 1970, Lucius Licinius Secundus liberto de Lucius Licinius Sura, Pyrenae 6, 167-184.

RODRÍGUEZ NEILA, J. F., 1981, Sociedad y administración en la Bética romana, Monte de Piedad y Caja de Ahorros, Córdoba.

ROMERO PÉREZ, M., 1993/94, La necrópolis romana de las Maravillas. Bobadilla. Málaga, Mainake 15-16, 195 -222.

ROMERO PÉREZ, M. y VARGAS VÁZQUEZ, S., 2017, La villa romana de Bobadilla (AntequeraMálaga), ROMVLA 16, 119-138.

ROSS TAYLOR, L., 1961, Freedmen and Freeborn in the Epitaphs of Imperial Rome, AJPh/American Journal of Philology 82, 113-132.

RUIZ DE ARBULO, J. (ed.), 2000, Tarraco 99. Arqueología de una capital provincial romana, DAC, 3, Universitat Rovira i Virgili, Tarragona.

SALLER, R. y SHAW, B. D., 1984, Tombstones and Roman Family Relations in the Principate: Civilians, Soldiers and Slaves, Journal of Roman Studies 74, 124-156.

SALLER, R., 1997, Roman Kinship: Structure and Sentiment, en B. RAWSON y P. WEAVER (eds.),
The Roman family in Italy, Status, sentiment, space, Clarendon, Oxford, 7-34.

SALWAY, B., 1994, What's in a Name? A Survey of Roman Onomastic Practice from c. 700 B.C. to A. D. 700., Journal of Roman Studies 84, 122-145.

SCHEIDEL, W., 1997, Quantifying the Sources of Slaves in the Early Roman Empire, Journal of Roman Studies 87, 156-169.

SCHULTEN, A., 1948, Tarraco, Ed. Bosch, Barcelona.

SCHULZE-OBEN, H., 1989, Freigelassene in den Städten des Römischen Hispanien. Juristische, wirtschaftliche und soziale Stellung nach dem Zeugnis der Inschriften, Rudolf Habelt, Bonn.

SERRANO DELGADO, J. M., 1988a, Estatus y promoción social de los libertos en Hispania Romana, Universidad de Granada, Granada.

SERRANO DELGADO, J. M., 1988b, Sevir Augustalis-Magister Larum Augustalium en Tarraco, en G. PEREIRA MENAUT (ed.), I Congreso Peninsular de Historia Antigua 3, Universidad de Santiago de Compostela, 23-25.

SOLIN, H., 1982, Die Griechischen Personennamen in Rom: ein Namenbuch, Walter de Gruyter \& Co., Berlín.

SOLIN, H. y SALOMIES, O., 1988, Repertorium nominum gentilium et cognominum Latinorum, Hildesheim, Olms-Weidmann, Zürich-Nueva York.

SOLIN, H., 1990, Namenpaare: eine Studie zur römischen Namengebung, Societas Scientiarum Fennica, Helsinki.

STARR, C. G. Jr., 1942, Verna, Classical Philology 37, 3, 314-317.

TREGGIARI, S., 1971, Libertine Ladies, The Classical World 64 (6), 196-198.

TREGGIARI, S., 1975, Family life among the staff if the Volusii, TAPhA/Transactions of the American Philological Association 105, 393-401.

TREGGIARI, S., 1976, Jobs for Women, AJAH/ American Journal of Ancient History 1, 76-104. 
TREGGIARI, S., 1991, Roman Marriage. Iusti Coniuges from the Time of Cicero to the Time of Ulpian, Clarendon Press of Oxford University Press, Nueva York.

VERBOVEN, K., 2012, The Freedman Economy of Roman Italy, en S. BELL y T. RAMSBY (eds.), Free at Last! The Impact of Freed Slaves on the Roman Empire, Bristol Classical Press, Londres, 88-109.

WACKE, A., 1989, Manumissio matrimonii causa: le marriage d'affranchies d'après les lois
d'Auguste, Revue historique de droit français et étranger 67, 413-428.

WEAVER, P. R. C., 1972, Familia Caesaris: a social study of the emperor's freedmen and slaves, Cambridge University Press, Cambridge.

WEAVER, P. R. C., 1992, The Status of Children in Mixed Marriages, en B. RAWSON (ed.), The family in ancient Rome: new perspectives, Croom Helm, Londres. 